\title{
Cuba's HIV/AIDS Program: Controversy, Care and Cultural Shift
}

\section{By Conner Gorry}

In 1986, Cuba made public health history - and headlines, largely unfavorable[1-3] - when health authorities on the island implemented a quarantine policy for people evidencing symptoms of AIDS. The unprecedented 'sanatoria' policy sparked a turbulent international debate when it was initiated, but received scant attention when it was amended in 1993 and later repealed. Controversy aside, this and subsequent modifications to Cuba's national HIVIAIDS prevention and control program have helped keep prevalence on the island to $0.1 \%$, the lowest rate in the Americas.[4] With just 31 cases of mother-to-child HIV transmission since 1986, and infection through blood and hemoderivatives virtually eliminated,[5] the Cuban response to HIVIAIDS may provide useful strategies to other countries, especially in the Global South.

The need for practical, sustainable HIV programs in developing countries, where the disease burden is greatest, is urgent. Of the estimated 33.2 million people with HIV in 2007, 22.5 million were from sub-Saharan Africa, where the adult prevalence rate is $5.0 \%$. Figures

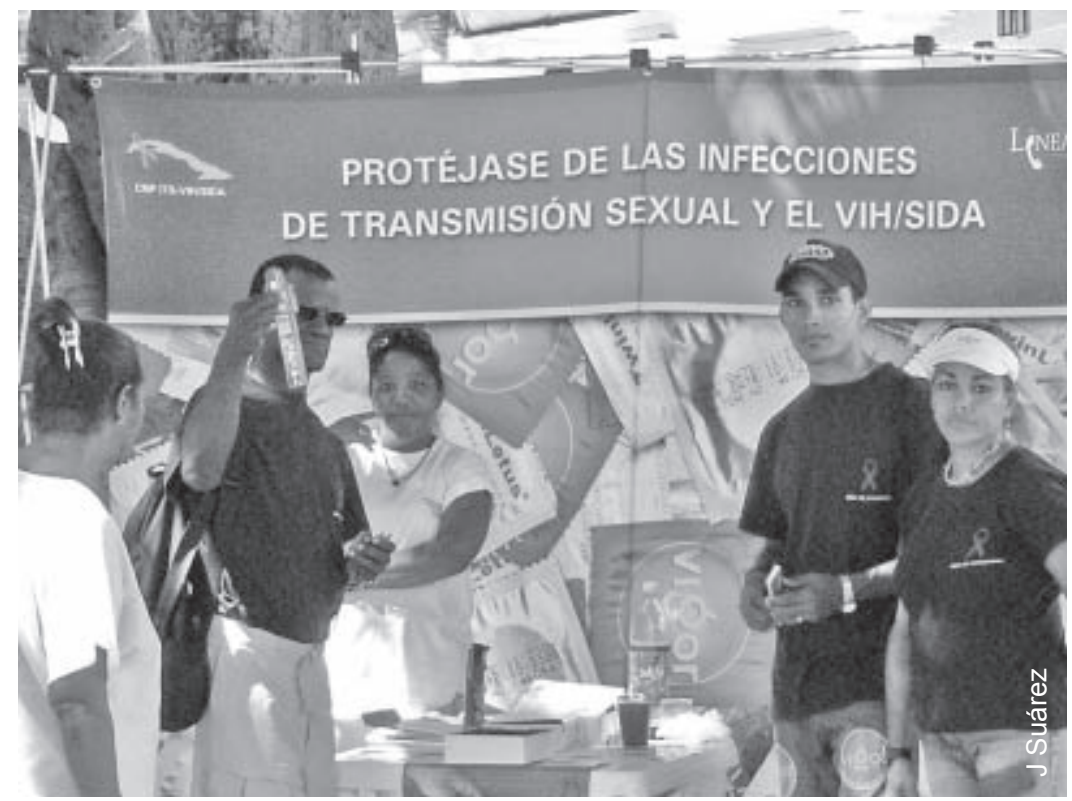

LíneAyuda recently celebrated its 10th anniversary in Havana handing out condoms and HIV prevention materials. for other parts of the Global South are similarly sobering, including the Caribbean, where the $1.0 \%$ adult prevalence rate is the world's second highest.[6] Although indicators have stabilized and even improved in some countries (eg Barbados, Trinidad \& Tobago, Cuba), AIDS-related mortality remains a leading cause of death among 25-44 year olds in the region.[7] More than any other indicator, AIDS mortality reflects the great divide between north and south: in 2007, 32,000 people from North America, and Western and Central Europe died of AIDS-related causes, compared to over 1.9 million in Latin America, South and Southeast Asia, and sub-Saharan Africa.[6]

Such grim statistics beg the question: how has a small, lowincome country like Cuba managed to achieve such a low HIV prevalence rate and keep AIDS-related deaths to 155 a year?[8]

\section{Pillars of Cuba's HIV/AIDS Program}

Cuba's HIVIAIDS response and outcomes are made possible by four fundamental factors:

- health care in Cuba is free, accessible, and universal;

- a coordinated national strategy allows for an integrated approach;

- $99 \%$ of HIV infections in Cuba are sexually transmitted;[9]

- a robust biotechnology industry makes antiretroviral therapy (ART) available to all HIV patients who need it.
Free, accessible, universal care: Since 1959, primary, secondary, and specialist health services in Cuba have been free to the entire population though a nationwide network of doctors' offices, clinics, hospitals, and research and reference centers. The primary care program locates family doctor-and-nurse teams in neighborhoods, bolstered by local polyclinics, referred to as the "backbone of Cuba's heath system" by Dr Cristina Luna, National Director of Ambulatory Care. There are currently 498 polyclinics across the island, offering primary care referral services in pediatrics, ob-gyn, internal medicine and other specialties, as well as services in dentistry, clinical laboratories, allergy testing, and physical rehabilitation, among others.[10] This primary care focus has helped Cuba achieve health parity with developing countries for major indicators, including life expectancy, infant mortality, and

\section{HIV/AIDS in Cuba, Cumulative Data 1985 - 2007}

Cuba's HIVIAIDS profile is predominantly urban, adult and male, with men who have sex with men (MSM) constituting the overwhelming majority of people with HIV on the island. Over $99 \%$ of HIV infections are through sexual relations.

Cumulative total of seropositive people detected

Cumulative $\%$ of seropositive people detected who are from Havana City

Cumulative \% of seropositive people who are male

Cumulative \% of seropositive males who are MSM

Cumulative total of AIDS cases

Cumulative total of AIDS-related deaths

Number of people currently receiving ART

Annual average number of HIV tests
9,304

$54 \%$

$81 \%$

$84 \%$

3,492

1,582

3,123

1.6 million

Source: National STI/HIVIAIDS Program, Epidemiology Department, Ministry of Public Health. June 2008 
under-5 mortality,[4] and has rendered the Cuban system better prepared to respond to emerging and re-emerging diseases, including HIV.

One example of the synergy between Cuba's primary health care network and HIV response is the low prevalence of mother-tochild transmission (MTCT). This low rate is achieved through early diagnosis and treatment. Under Cuba's National Program for Maternal-Child Health (PAMI), pregnant women are tested for HIV in their first trimester, and those who test positive are offered antiretroviral therapy. Treatment includes zidovudine beginning in the 14th week (unless the woman is already taking ARVs); best practices include caesarean sections and government-provided breast milk substitutes. It is worth noting that while taking ARVs is optional, $100 \%$ of HIV positive pregnant women opted for ARV treatment to prevent mother-to-child transmission in 2006 and 2007.[5] PAMI provides a continuum of care to women from adolescence through pregnancy and childbirth, and to children from birth to adolescence. In practice, this means an average of 12 pre-natal check-ups; in-hospital births by skilled medical personnel for $99.9 \%$ of pregnant women; and specialist services for high-risk pregnancies.

Coordinated national strategy: In 2003, United Nations member states agreed upon three principles for coordinating a national response to HIVIAIDS: establish a national monitoring and evaluation system; convene a national, multi-sector coordinating authority; and formulate an action framework to provide a basis for intersectoral work.[11] Known as the 'Three Ones,' Cuba began implementing these principles in 1983 (prior to detecting HIV on the island) with the establishment of the National AIDS Commission, a multi-disciplinary team that included the Epidemiological Surveillance System, to monitor for clinical markers of HIV such as pneumonia and Kaposi's sarcoma.[12] When the first cases of HIV were detected in late 1985 and early 1986, health authorities took measures based on classic infectious disease control, including setting up a network of sanatoriums, establishing the National Program for the Prevention and Control of STI/ HIVIAIDS, and founding the Working Group for Confronting and Fighting AIDS (GOPELS) to coordinate national HIVIAIDS efforts across all sectors.

The educational component of Cuba's program is directed by the National STI/HIVIAIDS Prevention Center, founded in 1998. The Center designs, implements and evaluates all educational and prevention activities nationwide, and is the Global Fund to Fight AIDS, Tuberculosis \& Malaria's technical partner in Cuba. Together GOPELS, the National Prevention Center, Ministry of Public Health and other entities designed Cuba's National STI/HIVIAIDS Strategic Plan 2001-2006 - the last of the Three Ones.

Epidemiology: Once it was understood that HIV could be transmitted through blood, Cuba destroyed all potentially infected blood and blood products, some 20,000 containers.[9] A product pipeline for hemoderivatives was established to offset the lost blood product imports, and HIV testing of all blood became national policy in 1986. Eventually, with advances in HIV and epidemiological research, Cuba pinpointed sexual relations as the main transmission route. Later studies revealed the overwhelming majority of Cubans infected were men who have sex with other men (MSM), allowing authorities to design a targeted education, prevention

\section{Cuba's HIV/AIDS Response and International Cooperation}

Cuba's HIVIAIDS strategy includes working with a variety of international organizations to evaluate and strengthen the national program, including:

- United Nations agencies: UNDP, UNICEF, UNAIDS, UNESCO

- Pan American Health Organization (PAHO) and the World Health Organization (WHO)

- Doctors without Borders (Spain \& Holland)

- Médicos del Mundo (Spain)

- HIVOS (Holland)

- Global Fund to Fight AIDS, Tuberculosis \& Malaria

The Global Fund has supported Cuba's national HIVIAIDS program through three rounds of funding (2003, 2006 \& 2008 ) totaling over USD $\$ 50$ million. Primary uses of these funds included distributing and socially marketing condoms (over 90 million condoms were sold and distributed in 2004 alone), training health promoters, and counseling services. According to the Global Fund Grant Scorecard, Cuba managed the funds well and met — or in some cases surpassed - these targets:

- $154 \%$ of counseling for people aged 15 to 34

- $100 \%$ of HIVISTI educational program for students

- $241 \%$ of peer educator training

- $116 \%$ of condom distribution

Source: Cuba's HIVIAIDS Strategy: An Integrated, Rights-Based Approach, Oxfam. July 2008.

and treatment program for vulnerable groups as well as the general population.

Biotechnology capacity: Since the founding of the Center for Genetic Engineering and Biotechnology in 1986 and other research institutes in the Western Havana Scientific Pole thereafter, Cuba has developed a biotechnology industry that produces vaccines, therapeutic cancer treatments, and generic drugs, with multiple biotech products registered in 55 countries. Furthermore, Cuba meets $80 \%$ of its prescription drug needs with domestically manufactured products, including antiretrovirals (ARVs) used to treat HIVIAIDS.[13] In 2003, the country achieved free, universal antiretroviral therapy for those who need it with its own generic ARVs. Subsequently, AIDS-related mortality dropped from $24.3 \%$ in 2000 to $6.25 \%$ in 2006.[5]

\section{Practical Features of Cuba's HIV/AIDS Program}

An approach that integrates prevention, treatment, and care is the cornerstone of all practical HIVIAIDS programs, including Cuba's. Education and early detection are the fundamental principles of prevention activities, which emphasize the following elements:

- peer group format

- participatory methodology

- intersectoral approach

- involving people with HIV in program design and implementation 


\section{Feature}

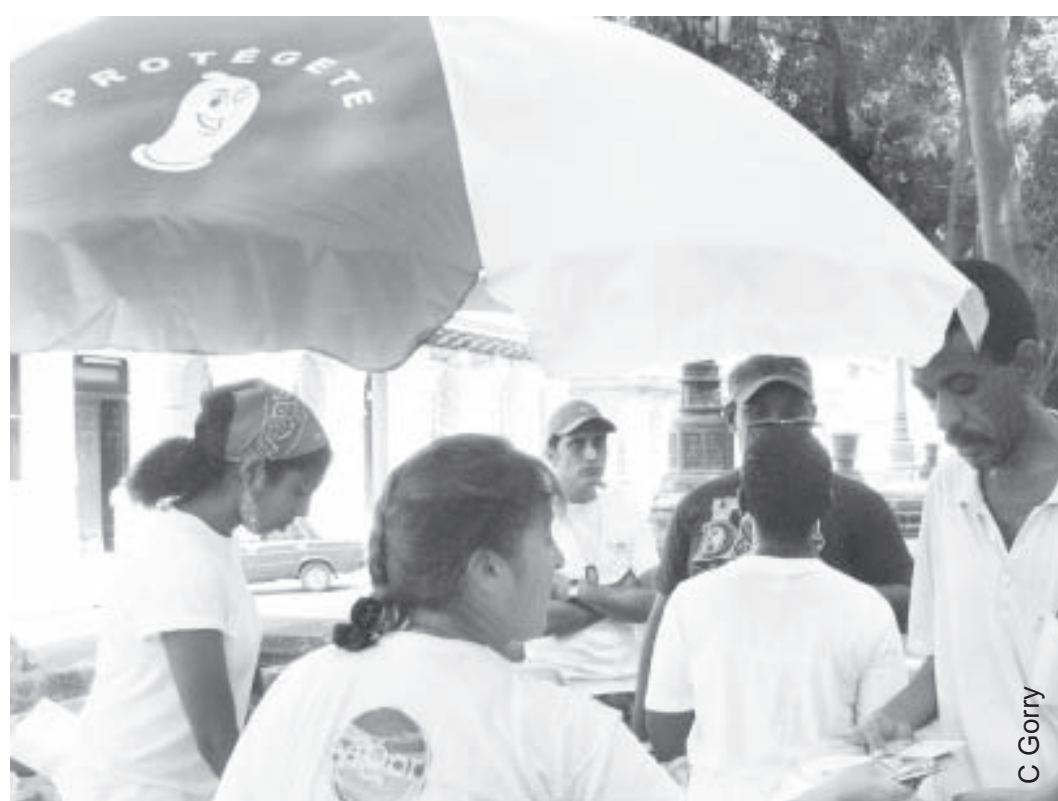

Central Havana's Prado promenade was abuzz with HIV prevention activities during LíneAyuda's 10th anniversary celebration.

These elements guide the National STI/HIVIAIDS Prevention Center's core activities, which include health promoter training; design, implementation and evaluation of educational materials and prevention activities; condom and lubricant distribution; and counseling. Longstanding projects such as Carrito por la Vida (Little Car for Life) and HSH (Hombres que tienen sexo con hombres) - projects designed and implemented by and for young people and men who have sex with men, respectively - are indicative of the Center's participatory, peer-group outreach efforts. By the end of 2007, 4,528 youth volunteers and 1,397 HIV counselors had been trained and were working in HIV prevention and counseling. In addition, a variety of resources provide anonymous, confidential counseling, including 304 Cara a Cara (Face-to-Face) offices and 15 LíneAyuda (Help Line) nodes nationwide. Established in 1998, this telephone hotline had received over 110,000 calls by the end of 2007, with an average of 36 a day.[5]

As the Cuban prevention program has matured, new, innovative projects have been introduced, including Salud y Belleza (Health and Beauty: HIV prevention by hairdressers in salons), Afroaché (health promotion by practitioners of Cuban religions of African origin), and Jóvenes por la Vida (Youth for Life), which includes a rollerblading team of health promoters distributing condoms and prevention information on the streets of Havana.

Cuba's intersectoral approach actively involves a broad range of organizations in HIV prevention and advocacy, including the Federation of Cuban Women (FMC), the Ministry of Education, the Ministry of Labor and Social Security, and the Ministry of Domestic Commerce, to mention a few. The latter guarantees the distribution of quality condoms in bars, cafeterias, restaurants and pharmacies, where they are widely available and sold for USD $\$ 0.01$. Condoms are also distributed at no charge at doctor's offices, and HIV prevention and testing centers. The Ministry of Education monitors the Sex Education and HIV Prevention Plan throughout the school system and designs curriculum on these topics for institutions of higher education.
Perhaps the most illustrative example of people with HIV helping to design and implement policy is the reversal of the mandatory quarantine policy: once it became evident that HIV was a preventable, manageable disease, residents of the nation's sanatoria lobbied for a reversal of the policy. Active participation in policy design continues today.

Early detection through active screening is another key element of Cuba's national prevention program. Over $93 \%$ of seropositive people in Cuba were diagnosed before the onset of AIDS.[5] HIV testing is mandatory for blood donors and inmates, and is voluntary for pregnant women, people with sexually transmitted infections and their sexual contacts, and the sexual contacts of people with HIV. Over one-third of Cubans diagnosed with HIV were detected through 'contact tracing' (testing the sexual partners of people with HIV).[5] A national network of anonymous testing sites, which follow informed consent guidelines, is available to people who voluntarily request testing.[14,15]

Once an HIV diagnosis is made, a specialist team with specific HIV and bioethics training meets with the person and explains the two types of care available - ambulatory and sanatorial. The team includes an epidemiologist, nurse, psychologist, and family doctor. Care is comprehensive and identical for both alternatives, although the former allows the person to live at home and receive care locally, while the latter provides residence and care in the sanatorium located nearest the person's home. (There are currently 12 sanatoria in Cuba.) Though mandatory quarantine is obsolete, people unwilling or unable to live independently may still be required to live in a sanatorium.

Underpinning Cuba's treatment and care approach is Learning to Live with HIV, a multi-week course to help people with HIV assimilate their condition while learning to "protect their own health and the health of others."[16] Participants receive their full salaries for the duration of the course, which includes general and scientific information about HIV and safer sex practices; assertiveness, selfcare and self-esteem training; ART adherence norms; instruction in proper diet and nutrition; and information about their legal rights and responsibilities.

During the course, participants are also encouraged to join one of the 98 mutual support groups located throughout the country; $94 \%$ of people with HIV have participated in one of these groups.[5] According to Dr Rigoberto López, Director of Havana's Comprehensive Care Center for People with HIVIAIDS, "Our objective is to prepare people for their new life and all the factors related to HIV prevention and their health, so they can return to their regular lives as soon and as prepared as possible."[17]

With the advent of antiretroviral therapy, HIV ceased being a death sentence and became a manageable, chronic disease, although not right away, and not in a resource-strapped country like Cuba. When AZT was first recommended as monotherapy in 1987, "We couldn't treat everyone; it was too expensive," says Dr Jorge Pérez, Vice Director of the Pedro Kourí Institute of Tropical Medicine, the national reference center for treating the opportunistic infections associated with HIVIAIDS. "So we started treating all the children, immediately... and then we started working on the protease level and got together people from the university, 


\section{Generic Antiretrovirals Produced in Cuba}

\author{
Nucleoside reverse transcriptase inhibitors \\ - Zidovudine (AZT) \\ - Didanosine (DDI) \\ - Stavudine (D4T) \\ - Lamivudine (3TC) \\ - Zalcitabine (DDC) \\ Non-nucleoside reverse transcriptase inhibitors \\ - Nevirapine (NVP) \\ Protease inhibitors \\ - Indinavir (IDV)
}

Source: Pautas Cubanas para el tratamiento y manejo de los pacientes VIH/SIDA sometidos a Terapéutica Antiretroviral. Pedro Kourí Institute of Tropical Medicine. 2003.

biotechnology, and the pharmaceutical industry, and asked, 'What are we going to do?' And we decided the ideal would be to build on experience with other generics and develop a Cuban generic antiretroviral therapy."[18] The goal was reached in 2001. The criteria for initiating ART follows the recommendations of the CDC's Panel on Clinical Practices for the Treatment of HIV.[14,19]

\section{Ongoing Challenges}

For a low-income country, Cuba has made unprecedented strides in curbing mother-to-child transmission, HIV infection through blood transfusions, and AIDS mortality. Nevertheless, challenges remain. Chief among them are resource scarcity and an adverse economic climate, HIV stigma, and the disease burden among men who have sex with other men.

Resource scarcity and economic climate: Cuba faces many economic realities shared by other developing nations except for one important, distinguishing factor: the country has been under an economic and financial embargo imposed by the United States for nearly 50 years. In practice, this means Cuba is barred from normal bilateral trade that would allow it to buy medicine, technology, equipment, and replacement parts from US manufacturers and their subsidiaries. As more Cubans begin to require second line ART, this barrier to life-prolonging medicine could be felt more acutely. On the upside, a Cuban generic lamivudinestavudine-nevirapine combination ARV will be available soon, and domestic production of nelfinavir, efavirenz, abacavir, and saquinavir are in different stages of development.[20]

HIV stigma: The Cuban constitution protects rights to housing, health care, and employment for all Cubans, reinforced by specific resolutions relating to people with HIV. Even so, discrimination in the form of 'silent stigma' or breaches of confidentiality still exist. Evidence that this was occurring in health care settings led Cuban authorities to develop specialized training for health care professionals, including dentists and nurses. The 20-hour course is designed to ensure comprehensive, dignified care for people with HIV and includes components on nutrition, ART adherence, biosafety, counseling techniques, prevention, and sensitivity training. Recent research shows health sector dis- crimination has declined since the introduction of the course and the advent of ART, which has transformed HIV into a manageable chronic disease.[21,22] Now that ambulatory care is standard for most Cubans with HIV, non-discriminatory care must also become standard. Unfortunately, recent instability and readjustments in the family doctor system has resulted in "overworked doctors... and weakened the health care link closest to the community,"[23] which may make the trend harder to sustain.

MSM: Men who have sex with men are - overwhelmingly - Cuba's most vulnerable group. Widespread machismo and homophobia typically work against HIV prevention, since rushed, clandestine or semi-public sexual encounters are not conducive to negotiating condom use or to partner stability. Treatment can also be adversely affected by such biases when a person with HIV does not have family support for ART adherence, proper nutrition or simply someone to talk to about their health. Determined to take a proactive, educational approach, Cuban health authorities launched a national sexual diversity and HIV awareness campaign for the first time in a coordinated, comprehensive way on May 17, 2008, International Day against Homophobia. This campaign is taking to the airwaves, movie theaters and newsstands in an effort to destigmatize sexual diversity and promote sexual health, particularly among men who have sex with other men. A TV serial with gay and HIV-positive characters; primetime public service announcements about health, nutrition and respect for people with HIV; and a 10-part radio series about sexual diversity are ongoing components. Furthermore, Cuba's participation in the International Day against Homophobia included the largest official gathering of LGBT (lesbian-gay-bisexual-transgender) people in the island's history, participating in debates and panels, and getting tested for HIV.

Cuba's experience with HIVIAIDS sets an example for achieving positive outcomes under adverse economic conditions. Key to these outcomes is the synergy between the free, universal health care system and a well-coordinated national HIVIAIDS strategy that emphasizes education, prevention, treatment and dignified care. The Cuban strategy has also proved flexible in response to changes in cultural attitudes and behavior. -1 -

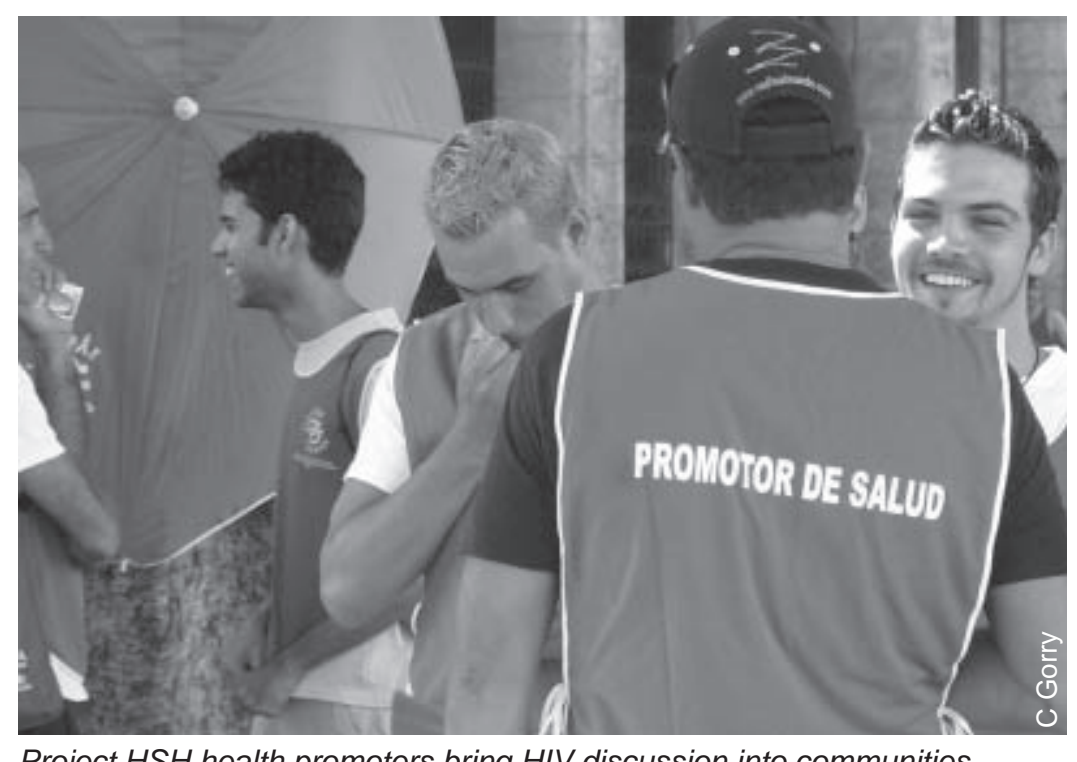




\section{Feature}

\section{References \& Notes}

1. Pérez-Stable EJ. Cuba's response to the HIV epidemic. AJPH. 1991;81(5):563-67.

2. Zonana VF. Cuba's AIDS quarantine center called 'frightening.' The Los Angeles Times. 1988 Nov 4; Sect. 1:1 (col. 5).

3. Wojcik M, Martin T, Closen M, Isaacman S. An outside critique of Cuba's AIDS program [abstract]. Int Conf AIDS. 1993;Jun 6-11; 9:924

4. World Health Organization. World health statistics 2008. Geneva: World Health Organization; 2008.

5. Ministerio de Salud Pública. Informe nacional sobre los progresos realizados en la aplicación del UNGASS. La Habana (Cuba): Ministerio de Salud Pública; 2008.

6. UNAIDS. AIDS epidemic update. Geneva: UNAIDS; 2007.

7. UNAIDS. Caribbean: AIDS epidemic update regional summary. Geneva: UNAIDS; 2008

8. Ministerio de Salud Pública. Anuario Estadística de Salud 2007. Havana: Ministerio de Salud Pública;2008.

9. Lantero MI, Waller J, Joanes J, Pérez J, Torres R, Santín M, et al. Cuba In: Beck EJ, Mays N, Whiteside AW, Zuniga JM. The HIV Pandemic: Local and global implications. New York: Oxford University Press; 2006. p 379-92.

10. Reed G. Cuba's primary health care revolution: 30 years on. Bulletin of the World Health Organization. 2008;86(5)

11. UNAIDS. "Three ones:" key principles [conference paper]. Geneva: UNAIDS; 2004:25 Apr.

12. Ministerio de Salud Pública. Plan estratégico nacional ITS/VIH/SIDA, 20012006. La Habana (Cuba): Ministerio de Salud Pública; Jan 2001.

13. Evenson D. Cuba's biotechnology revolution. MEDICC Review. 2007 Fall;9(1):8-10

14. Cancio I, Sánchez J, Reymond V, López VJ. Información básica sobre la atención integral a personas con $\mathrm{VIH} /$ sida: material dirigido a los equipos de aten- ción primaria y secundaria de salud. Centro Nacional de Prevención de las ITS/VIH/SIDA. 1st ed. Havana: Ediciones Lazo Adentro; 2006.

15. Pérez J, Pérez D, González I, Diaz Jidy M, Orta M, Aragonés C, et al. Approaches to the management of HIVIAIDS in Cuba. Geneva: World Health Organization; 2004

16. Álvarez A, Pérez F, Fonseca N, Chacón L, Amargós GM, Villalón M, et al. Conociendo sobre VIH: Manual para médicos de la familia y el personal de salud en Cuba. CNPITS-VIH/SIDA. Habana; 2004

17. López, Rigoberto (Director, Centro de Atención Integral a Personas con VIH/ SIDA). Interviewed by the author, April 9, 2008.

18. Pérez, Jorge. Interviewed by the author, July 5, 2007

19. Dybul M, Fauci AS, Bartlett JG, Kaplan JE, Pau AK. Panel on Clinical Practices for the Treatment of HIV. Guidelines for using antiretroviral agents among HIVinfected adults and adolescents. Recommendations of the Panel on Clinical Practices for Treatment of HIV. MMWR Morb Mortal Wkly Rep 2002;51(RR7):1-55.

20. Ramírez F. Asiste Cuba a Conferencia sobre Sida con triada de antirretrovirales. Notimex. 2008 Aug 2.

21. Miñoso G, Valdés JR. Fuentes de apoyo y discriminación de las personas que viven con VIH/SIDA en provincias selccionadas en Cuba 2004. In: Ochoa R, Rojo N eds. Investigaciones sobre VIH en el contexto de la salud pública cubana. Habana: Centro Nacional de Prevención de las ITS-VIH/SIDA; 2006:97-104.

22. Castro A Khawja Y, González-Núñez I Sexuality, reproduction, and HIV in women: the impact of antitretroviral therapy in elective pregancies in Cuba. AIDS. 2007;21(5):S49-S54.

23. Edith D, Terrero A. Otra vuelta de rosca. Bohemia. [serial on the Internet]. 2008 Mar 24. Available from: http://www.bohemia.cu/2008/03/24/ encuba/salud.html. 